\title{
Theoretical analysis and experimental research on the energy dissipation of rock crushing based on fractal theory
}

Yong Deng ${ }^{1,2}$, Mian Chen ${ }^{1,2, *}$, Yan Jin ${ }^{1,2}$ and Daiwu Zou ${ }^{1,2}$

${ }^{1}$ College of Petroleum Engineering, China University of Petroleum, Beijing 102249, China

${ }^{2}$ State Key Laboratory of Petroleum Resources and Prospecting, Beijing 102249, China

*Corresponding Author: Mian Chen

Corresponding Author's Institution: College of Petroleum Engineering, China University of Petroleum, Beijing 102249, China

Corresponding Author’s E-mail: chenmiancup@163.com

First Author: Yong Deng

First Author's Institution: College of Petroleum Engineering, China University of Petroleum, Beijing 102249, China

First Author's E-mail: dengyong2012@yeah.net

\begin{abstract}
The relationship between energy consumption and the rock fragment size distribution is a basic question in rock fragmentation. Based on fractal rock mechanics and fracture mechanics theory, a new model of energy consumption during rock fragmentation is proposed. Moreover, dynamic uniaxial compressive tests on granite and sandstone under five different impact velocities are conducted with the split Hopkinson pressure bar (SHPB) device, the fragment size distribution of broken rock is obtained by sieving and the energy dissipation in the process is analyzed. The results from the tests show that fragments resulting from rock breakage under impact loading exhibit fractal features; the larger the fractal dimension, the higher the degree of rock fragmentation. Notably, the energy consumption density is inversely correlated with the average size of the rock fragments: with an increasing energy consumption density, the average size decreases significantly and the fracture surface area increases accordingly. Additionally, the SHPB tests enable determination of the fracture surface energy of granite and sandstone, and the energy consumption density is calculated based on the theoretical model and found to be in good agreement with the experimental results.
\end{abstract}

Keywords: energy dissipation; rock fragmentation; fractal theory; SHPB; impact 


\section{Introduction}

With shallow oil and gas resources gradually decreasing, the target of oil and gas exploration and development has turned to deep strata in the form of deep and ultra-deep wells, which poses a serious challenge to underground rock engineering and deep drilling engineering. The use of impact energy to drill, a concept that has long been proposed, can enhance the efficiency of rock breaking and meet the demand of deep well drilling (Xu and Yu, 1984; Wang, 1999).

Research and experiments have indicated that the impact drilling technique is an effective and feasible method to break up rock in deep hard formations, offering great potential in geotechnical engineering and mining of petroleum and natural gas (Wiercigroch et al., 2005; Li et al., 2010; Akbari et al., 2011; Franca, 2011; Li et al., 2015). The dynamic fragmentation of rock is essentially a process of energy consumption, and energy dissipation analysis is essential to elucidate the mechanism of rock dynamic crushing. Furthermore, energy consumption is not only one of the important indicators to evaluate rock breaking efficiency but also forms a useful metric when optimizing the rate of impact drilling. A series of studies on the energy dissipation characteristics of rock crushing have been performed by a number of domestic and foreign scholars, and valuable research results have been obtained. For example, Hustrulid and Fairhurst (1971; 1972) investigated the energy transfer efficiency of percussive drilling and derived the minimum impact force for optimal energy transfer; Carpinteri et al. (2004) carried out an experimental investigation on concrete specimens under crushing and fragmentation over a large scale range to evaluate the influence of fragment size distribution on energy density dissipation. They concluded that energy density dissipation was proportional to the characteristic size of rock fragments using fractal concepts, but did not obtain a specific functional expression between the dissipated energy and rock fragment size distribution. Lundberg et al. $(2006 ; 2010)$ studied the energy efficiency and the influence of loading waveform on energy transfer efficiency in the percussive drilling process and theoretically obtained the optimum waveform that can produce an energy transfer efficiency equal to 1 (though this was not available in practice). Marian et al. (2008) investigated the vibrational energy transfer for percussive drilling and proposed a new method of vibrational energy transfer from high-frequency low-amplitude to low-frequency high-amplitude mechanical vibrations. Sadrai et al. (2011) developed a high-velocity impact 
comminution apparatus to study the energy efficiency of rock breakage; experimental results suggested that energy efficiency of rock breakage can be improved by two or three times using high velocity impact for the same energy input level. Li et al. (1988) carried out experiments to study the effects of duration and amplitude of stress wave on energy dissipation in sandstone; the results showed that energy absorption per unit volume of rock increased with increasing duration and amplitude of the stress wave, but that excessive duration and amplitude in stress waves would lead to additional energy loss. Xu et al. (2010) studied the effects of confining pressure on energy dissipation of rock under cyclic impact loads; the results indicated that energy absorption increased with increasing number of cyclic impacts but decreased with increasing confining pressure under the same strain rate.

The theoretical and experimental studies on energy dissipation of rock fragmentation cited above primarily concentrated on the relationships among energy consumption, stress waveform, strain rate and confining pressure (see, e.g., Hustrulid and Fairhurst, 1971, 1972; Lundberg et al., 2006, 2010; Li et al., 1988; Xu et al., 2010). However, there has been little research on the quantitative relation between energy consumption and fragment size distribution (Carpinteri et al., 2004; Li et al., 2009). Therefore, this paper is focused on developing a quantitative relationship between energy consumption and rock fragment distribution by means of fractal rock mechanics and fracture mechanics theory and presents a theoretical analysis and results of indoor experiments. Dynamic uniaxial compressive tests on granite and sandstone under five different impact velocities are performed using the large diameter split Hopkinson pressure bar (SHPB) device. Energy density absorption and fracture surface energy of test granite and sandstone under SHPB test are obtained, and the test results indicate that the energy consumption density of rock crushing under impact load is basically consistent with the theoretically derived value, which demonstrates the validity of the theoretical model.

\section{Fractal energy consumption model of rock crushing}

Fractal geometry was originally developed by Mandelbrot to describe highly irregular and self-similar objects (Mandelbrot, 1982); subsequently, fractal theory was applied to many other scientific fields (Perfect, 1997; Lai et al., 2015; Hu et al., 2016). In the field of rock fragmentation, numerous studies have showed that rock fragments exhibit fractal features that reflect the energy 
dissipation process (Nagahama, 1993; Xie, 1996; Carpinteri et al., 2004). Macroscopic breakage of rock material under a load is characterized by a small group of fragments, whereas minor fracture consists of smaller crack evolution and aggregation, and this similar behavior leads the broken fragments and energy dissipation process to exhibit self-similarity. Using the basic definition of a fractal (Turcotte, 1986), the number of fragments $(N)$ with size is larger than $r$ exhibits a power function correlation with $r$; that is:

$$
N(r)=C_{0} r^{-D_{f}}
$$

where $D_{f}$ is the fractal dimension, $r$ is the size of fragments in $\mathrm{mm}$, and $C_{0}$ is a proportionality coefficient.

It can be concluded from the equation above that the cumulative distribution of fragments with size smaller than $r$ is

$$
P(r)=1-\left(\frac{r_{\min }}{r}\right)^{D_{f}}
$$

Then, the total fracture surface area of fragments can be obtained by integration:

$$
A=\int_{r_{\min }}^{r_{\max }} N_{t}\left(4 \pi r^{2}\right) d P(r)
$$

where $N_{t}$ is the total number of rock fragments, $r_{\min }$ is the minimum size of fragments, and $r_{\max }$ is the maximum size of fragments.

Inserting Equation (2) into Equation (3), the total surface area can be written as:

$$
A=4 \pi N_{t} \frac{D_{f}}{D_{f}-2} r_{\text {min }}^{D_{f}}\left(\frac{1}{r_{\min }^{D_{f}-2}}-\frac{1}{r_{\max }^{D_{f}-2}}\right) \cong\left\{\begin{array}{l}
4 \pi N_{t} \frac{D_{f}}{D_{f}-2} r_{\min }^{2}, D_{f}>2 \\
4 \pi N_{t} \frac{D_{f}}{2-D_{f}} r_{\min }^{D_{f}} r_{\max }^{2-D_{f}}, D_{f}<2
\end{array}\right.
$$

Similarly, the total volume of rock fragments can also be obtained by integration:

$$
\mathrm{V}=\int_{r_{\min }}^{r_{\max }} N_{t}\left(\frac{4}{3} \pi r^{3}\right) d P(r)=\frac{4}{3} \pi N_{t} \frac{D_{f}}{3-D_{f}} r_{\min }^{D_{f}}\left(r_{\max }^{3-D_{f}}-r_{\min }^{3-D_{f}}\right) \cong \frac{4}{3} \pi N_{t} \frac{D_{f}}{3-D_{f}} r_{\min }^{D_{f}} r_{\max }^{3-D_{f}} \text { (5) }
$$

Rock breaking is the process of new free surface formation. According to fracture mechanics theory (Griffith, 1921; Li et al., 2010), the energy dissipated to produce the new free surface in the 
fragmentation process is provided by the product of the surface energy $E_{s}$ and the total fracture surface area (the effect of initial surface area is negligible when the particle size after fragmentation is far smaller than the initial size of the rock):

$$
W=E_{s} A=\left\{\begin{array}{l}
3 E_{s} V\left(\frac{3-D_{f}}{D_{f}-2} \cdot r_{\min }^{2-D_{f}} \cdot r_{\max }^{D_{f}-3}\right), D_{f}>2 \\
3 E_{s} V\left(\frac{3-D_{f}}{2-D_{f}} \cdot \frac{1}{r_{\max }}\right), D_{f}<2
\end{array}\right.
$$

Then, the energy required for rock breaking per unit volume is defined as the energy consumption density:

$$
E_{v}=\frac{W}{V}=\left\{\begin{array}{l}
3 E_{s}\left(\frac{3-D_{f}}{D_{f}-2} \cdot r_{\min }^{2-D_{f}} \cdot r_{\max }^{D_{f}-3}\right), D_{f}>2 \\
3 E_{s}\left(\frac{3-D_{f}}{2-D_{f}} \cdot \frac{1}{r_{\max }}\right), D_{f}<2
\end{array}\right.
$$

Equation (7) is the fractal energy consumption density model of rock crushing, which can be directly determined by the rock fracture surface energy and fragment-size distribution.

\section{Experimental section}

\subsection{Materials and preparation}

The test materials used in SHPB impact testing are granite and sandstone with good integrity and homogeneity taken from the Tarim area. To reduce compositional and structural differences that might affect test results, all of the specimens are drilled from the same rock block. The rock samples are processed into cylindrical specimens of $\varphi 50 \mathrm{~mm} \times 25 \mathrm{~mm}$ using a vertical core machine, as shown in Figure 1. To ensure that the ends of rock samples are flat, smooth and parallel to each other in the horizontal direction as well as perpendicular to the vertical axis, a rock cutting machine and polishing machine are adopted to grind and polish the two end faces of the samples. In addition, before the SHPB tests, uniaxial compression tests are also conducted using the RTR-1500 electro-hydraulic and servo-controlled Rock Triaxial Testing System to obtain static mechanical parameters of the two types of rock. The characterization tests are performed in accordance with relevant ASTM standard practices (ASTM, 2002). The average mechanical property values of the rock are summarized in Table 1. 


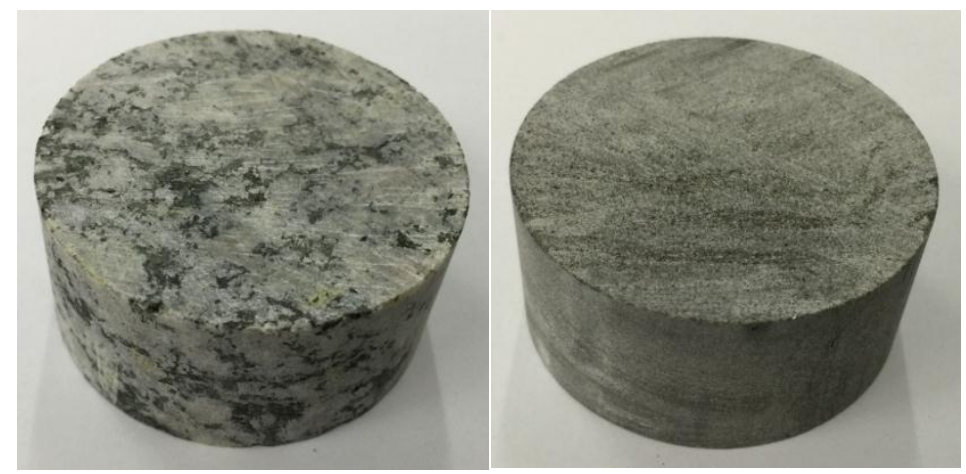

(a) Granite

(b) Sandstone

Fig. 1 Rock sample for SHPB impact test

Table 1 Static mechanical parameters of different rocks

\begin{tabular}{ccccc}
\hline $\begin{array}{c}\text { Rock } \\
\text { sample }\end{array}$ & $\begin{array}{c}\text { Density } \\
\left(\mathrm{kg} / \mathrm{m}^{3}\right)\end{array}$ & $\begin{array}{c}\text { Uniaxial compressive } \\
\text { strength }(\mathrm{MPa})\end{array}$ & $\begin{array}{c}\text { Elastic modulus } \\
(\mathrm{GPa})\end{array}$ & $\begin{array}{c}\text { Poisson } \\
\text { ratio }\end{array}$ \\
\hline Granite & 2680 & 96.03 & 39.27 & 0.171 \\
Sandstone & 2550 & 62.78 & 18.58 & 0.189 \\
\hline
\end{tabular}

\subsection{Experimental apparatus and method}

The $950 \mathrm{~mm}$ SHPB testing device is shown in Figure 2 and is composed of four parts: the main equipment, energy power system, test system and data-processing system. The main equipment consists of a launcher device, gun barrel, projectile (striker bar), incident bar, transmission bar, and energy absorption device. The energy power system includes an air compressor and high pressure air storage tank. The test system includes a projectile speed test system and ultra-dynamic strain test system. The pressure bar is constructed of high-strength maraging steel with a diameter of $50 \mathrm{~mm}$. The length of the incident bar and transmission bar is 2,000 mm, and the striker bar has a length of $400 \mathrm{~mm}$. The longitudinal sonic speed and elastic modulus of the bars are $5060 \mathrm{~m} / \mathrm{s}$ and $200 \mathrm{GPa}$, respectively. During the tests, the projectile is accelerated by compressed air and the light from the laser gun is used to measure impact velocity; the projectile then impacts the incident bar, which generates an elastic stress wave propagating through the elastic bar. At the specimen and incident bar interface, an elastic tensile stress wave is reflected back through the incident bar and a compressive stress wave travels forward through the specimen into the transmission bar. The strain signals of the incident wave, reflected wave and transmitted wave are measured by strain gauges, which are symmetrically mounted on the incident bar and the transmission bar. 

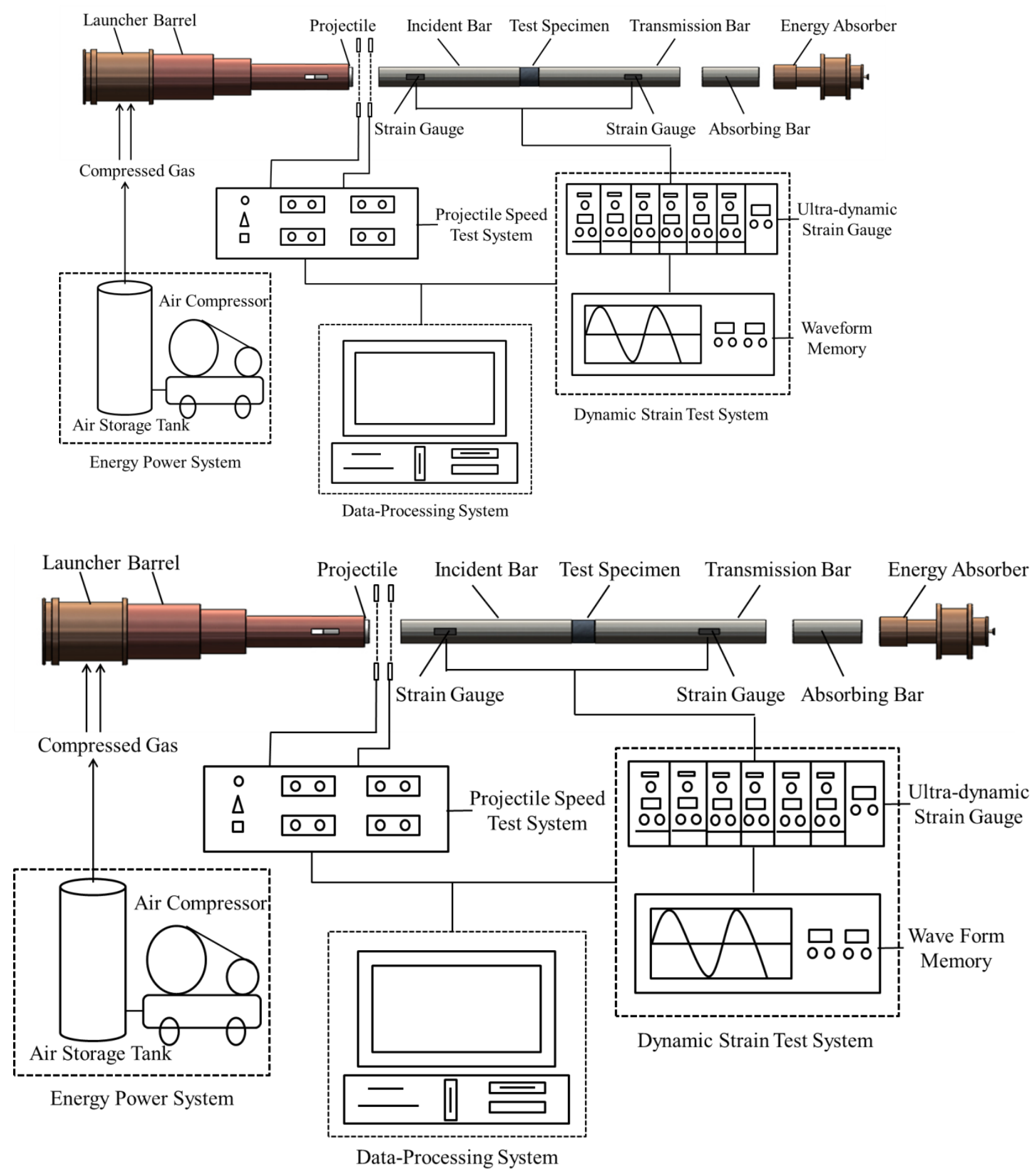

Fig. 2 Diagram of 50-mm diameter SHPB test system

To fully study the characteristics of energy dissipation of rock under impact loading, two types of rock (granite and sandstone) are selected, and five different impact velocity values (6.0 $\mathrm{m} / \mathrm{s}, 7.0 \mathrm{~m} / \mathrm{s}, 8.0 \mathrm{~m} / \mathrm{s}, 9.0 \mathrm{~m} / \mathrm{s}$, and $10.0 \mathrm{~m} / \mathrm{s}$ ) are selected. The different impact velocities are obtained by adjusting the impact pressures; five different pressure levels of $0.58,0.67,0.75,0.82$, 0.90MPa are determined to ensure the designed impact velocities. Before the SHPB test, the two 
end faces of the rock samples are treated with lubricant to assure good contact between the end faces and bars and to eliminate interface friction between the rock and elastic bars. When conducting the SHPB impact tests, the rock specimen is placed between the incident bar and transmission bar. The compressed air is pressurized according to the predefined pressure level to accelerate the projectile, known as the striker bar, that strikes the incident bar. The computerized data acquisition system then continuously records the three wave signals generated in the impact process.

\section{Results and discussion}

\subsection{Characteristics of rock fragment distribution}

Using equation (5), the mass of rock fragments with size smaller than $r_{i}$ can be expressed as

$$
M\left(<r_{i}\right) \cong \frac{4}{3} \pi N_{t} \rho \frac{D_{f}}{3-D_{f}} r_{\text {min }}^{D_{f}} r_{i}^{3-D_{f}}
$$

where $\rho$ is the material density; thus, the ratio of this partial mass to the total mass can be given as follows:

$$
y_{i}=\frac{M\left(<r_{i}\right)}{M} \cong\left(\frac{r_{i}}{r_{\max }}\right)^{3-D_{f}}
$$

The logarithmic version of Equation (9) becomes

$$
\ln y_{i}=\left(3-D_{f}\right) \ln \left(\frac{r_{i}}{r_{\text {max }}}\right)
$$

The value of $\left(3-D_{f}\right)$ in Eq. (10) can be quantified by sieving statistics; it represents the slope of the fitting line in the coordinate system of $\ln y_{i} \sim \ln \left(r_{i} / r_{\max }\right)$. Thus, the fractal dimensions of the rock fragments can then be determined.

To quantitatively and intuitively describe the degree of fragmentation, the average size of rock fragments is defined as

$$
d_{m}=\frac{\sum\left(\gamma_{i} \cdot r_{i}\right)}{\sum \gamma_{i}}
$$


where $r_{i}$ is the mean size of the fragments situated between sieves and successive mesh size and $\gamma_{i}$ is the mass fraction of fragments corresponding to the size of $r_{i}$.

After collecting the rock fragments generated in the SHPB impact tests, sieve tests are performed to obtain the distribution characteristics of the rock fragments. Standard sieves with bore diameters of $0.25,0.5,1.0,2.0,5.0,10.0,16.0,20.0,25.0,31.5 \mathrm{~mm}$ are adopted, and the fragment sieving results from the rock specimens are given in Table 2 (G represents granite, $S$ represents sandstone).

Table 2 Sieving test results of rock fragments

\begin{tabular}{ccccccccccc}
\hline Rock & \multicolumn{8}{c}{ Cumulative mass percentage at specific mesh size (\%) } \\
\cline { 2 - 12 } sample & $0.25 \mathrm{~mm}$ & $0.5 \mathrm{~mm}$ & $1 \mathrm{~mm}$ & $2 \mathrm{~mm}$ & $5 \mathrm{~mm}$ & $10 \mathrm{~mm}$ & $16 \mathrm{~mm}$ & $20 \mathrm{~mm}$ & $25 \mathrm{~mm}$ & $31.5 \mathrm{~mm}$ \\
\hline G-1 & 0.21 & 0.55 & 1.71 & 2.60 & 4.84 & 13.61 & 24.38 & 40.75 & 55.83 & 100 \\
G-2 & 0.22 & 0.53 & 1.70 & 2.85 & 5.78 & 14.10 & 23.46 & 56.10 & 68.58 & 100 \\
G-3 & 0.22 & 0.45 & 1.85 & 6.69 & 12.83 & 22.19 & 29.22 & 54.14 & 76.25 & 100 \\
G-4 & 2.59 & 4.36 & 8.32 & 13.65 & 22.11 & 31.23 & 51.28 & 75.60 & 85.01 & 100 \\
G-5 & 2.24 & 4.56 & 10.99 & 15.25 & 23.01 & 38.11 & 64.01 & 73.08 & 84.64 & 100 \\
\hline S-1 & 2.50 & 6.11 & 9.43 & 20.25 & 33.41 & 40.67 & 60.45 & 76.54 & 85.89 & 100 \\
S-2 & 4.59 & 7.28 & 15.21 & 21.28 & 31.03 & 48.79 & 68.33 & 77.06 & 88.21 & 100 \\
S-3 & 7.10 & 12.24 & 25.20 & 38.27 & 48.31 & 62.54 & 78.88 & 87.86 & 100 & 100 \\
S-4 & 8.62 & 15.31 & 26.40 & 38.48 & 47.72 & 68.13 & 83.07 & 91.44 & 100 & 100 \\
S-5 & 10.80 & 16.52 & 26.29 & 38.20 & 52.65 & 74.61 & 86.24 & 95.95 & 100 & 100 \\
\hline
\end{tabular}

According to equation (10) and the sieving results in Table 2, the diagrams of relative mass versus relative fragment size for the two types of rock under different impact loadings are shown in Figure 3, where $x=\ln \left(r_{i} / r_{\max }\right)$ and $y=\ln y_{i}$. The statistical correlation coefficients of the fitting straight lines in these figures are above 0.95 , which reveal that the distributions of rock fragments exhibit prominent fractal character.
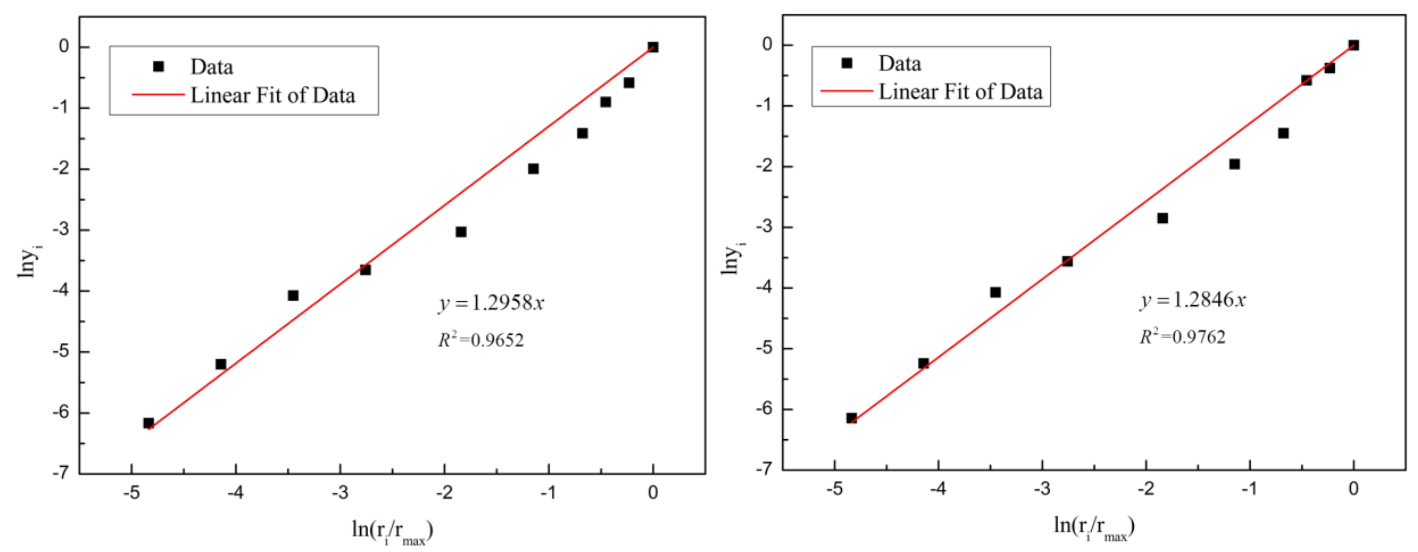
(a) Sample G-1

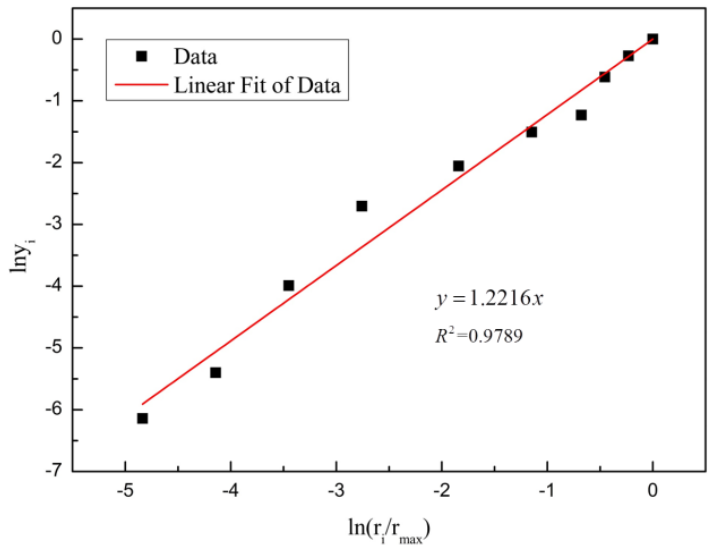

(c) Sample G-3

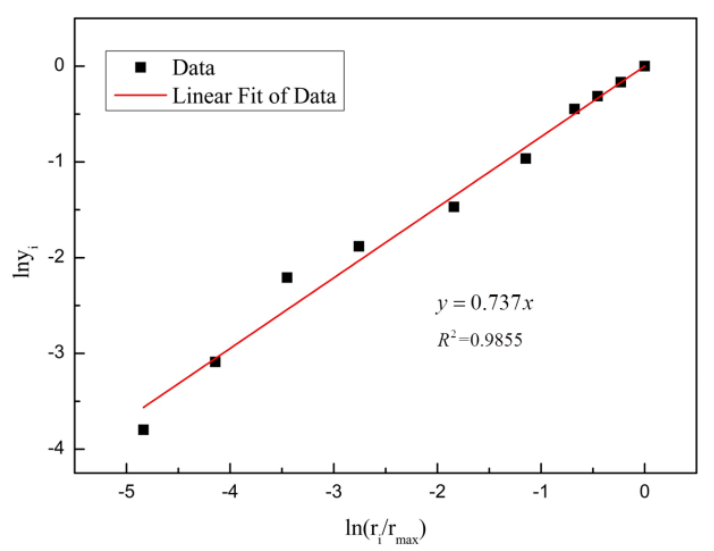

(e) Sample G-5

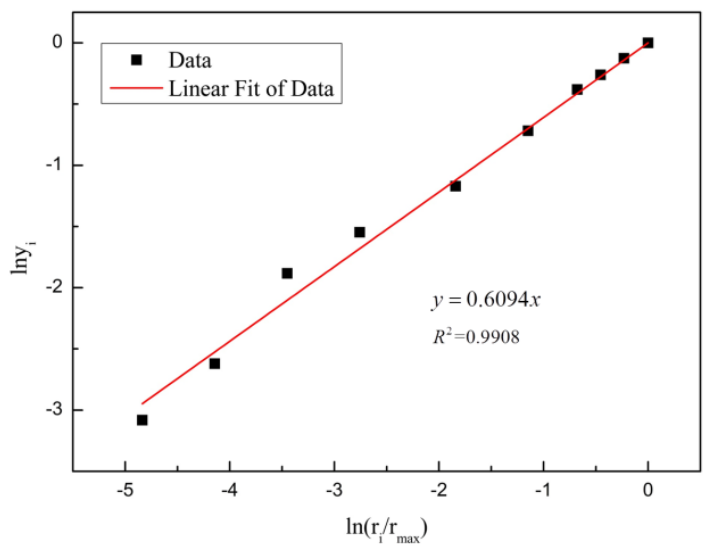

(g) Sample S-2 (b) Sample G-2

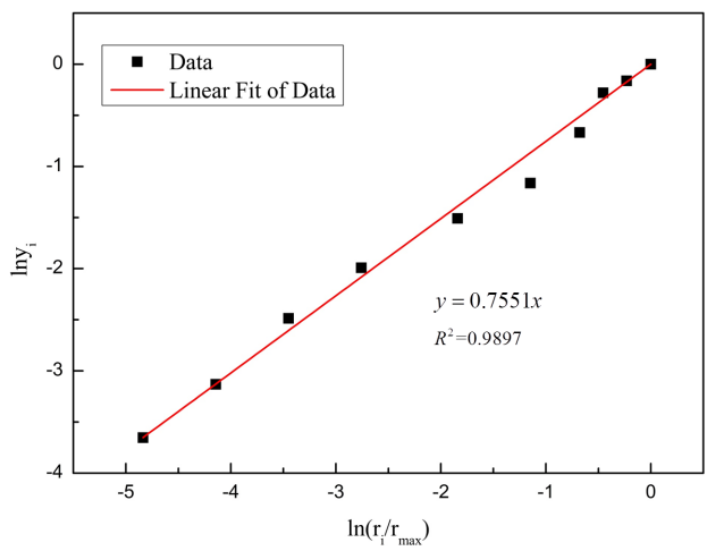

(d) Sample G-4

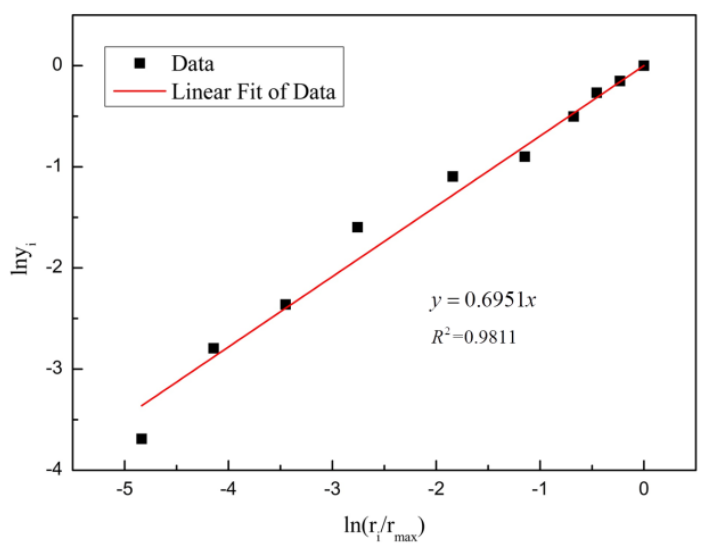

(f) Sample S-1

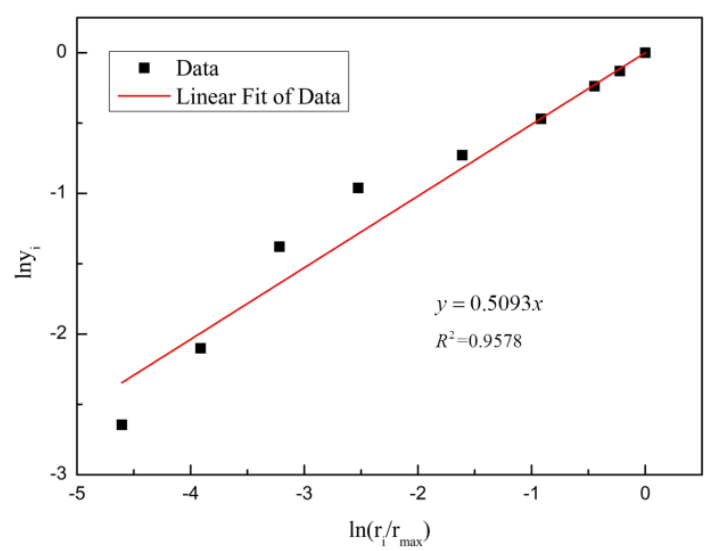

(h) Sample S-3 


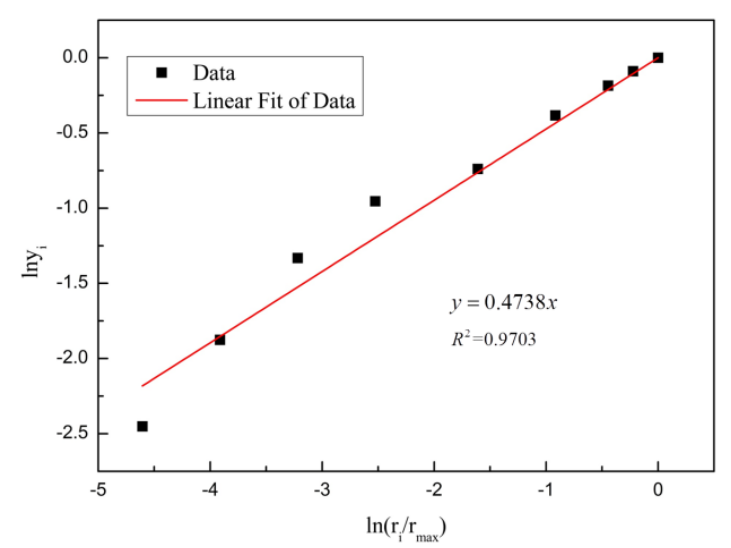

(i) Sample S-4

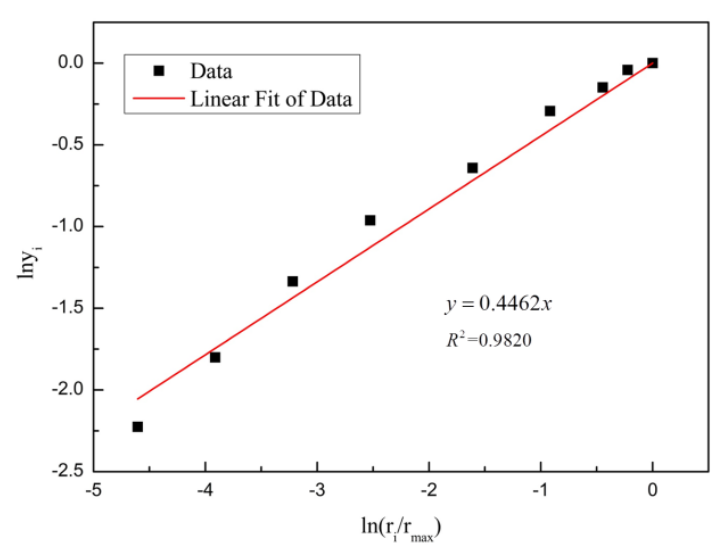

(j) Sample S-5

Fig. 3 Diagram of relative mass versus relative fragment size

The fractal dimensions and average size of fragments are calculated according to equations (10) and (11), and the results are given in Table 3. The failure modes of granite and sandstone under five different impact velocities are shown in Figure 4. As seen from Table 3 and Figure 4, with increasing impact velocity, the size of fragments significantly decreases, but the amount of fragments and fractal dimensions clearly increases, which indicates that the fractal dimension can be used to describe the degree of rock fragmentation: the larger the fractal dimension, the more comprehensive the rock breaking.

Table 3 Calculated fractal dimensions and average size

\begin{tabular}{ccccc}
\hline $\begin{array}{c}\text { Rock } \\
\text { sample }\end{array}$ & Fractal fitting equation & $\begin{array}{c}\text { Correlation } \\
\text { coefficient } \mathrm{R}^{2}\end{array}$ & $\begin{array}{c}\text { Fractal dimension } \\
\mathrm{D}_{\mathrm{f}}\end{array}$ & $\begin{array}{c}\text { Average size } \\
\mathrm{d}_{\mathrm{m}}(\mathrm{mm})\end{array}$ \\
\hline $\mathrm{G}-1$ & $\ln y_{i}=1.2958 \ln \left(r_{i} / r_{\max }\right)$ & 0.9625 & 1.7042 & 20.97 \\
$\mathrm{G}-2$ & $\ln y_{i}=1.2846 \ln \left(r_{i} / r_{\max }\right)$ & 0.9762 & 1.7154 & 19.52 \\
$\mathrm{G}-3$ & $\ln y_{i}=1.2216 \ln \left(r_{i} / r_{\max }\right)$ & 0.9789 & 1.7784 & 17.93 \\
$\mathrm{G}-4$ & $\ln y_{i}=0.7551 \ln \left(r_{i} / r_{\max }\right)$ & 0.9897 & 2.2449 & 14.07 \\
$\mathrm{G}-5$ & $\ln y_{i}=0.7370 \ln \left(r_{i} / r_{\max }\right)$ & 0.9855 & 2.263 & 13.29 \\
\hline $\mathrm{S}-1$ & $\ln y_{i}=0.6951 \ln \left(r_{i} / r_{\max }\right)$ & 0.9811 & 2.3049 & 12.77 \\
$\mathrm{~S}-2$ & $\ln y_{i}=0.6094 \ln \left(r_{i} / r_{\max }\right)$ & 0.9908 & 2.3906 & 11.78 \\
$\mathrm{~S}-3$ & $\ln y_{i}=0.5093 \ln \left(r_{i} / r_{\max }\right)$ & 0.9578 & 2.4907 & 8.21 \\
\hline
\end{tabular}




\begin{tabular}{lllll}
\hline S-4 & $\ln y_{i}=0.4738 \ln \left(r_{i} / r_{\text {max }}\right)$ & 0.9703 & 2.5262 & 7.52 \\
S-5 & $\ln y_{i}=0.4462 \ln \left(r_{i} / r_{\max }\right)$ & 0.9820 & 2.5538 & 6.59 \\
\hline
\end{tabular}

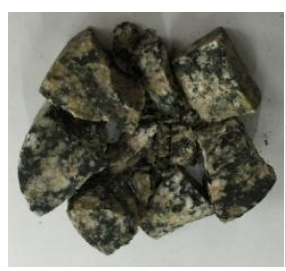

(a) $6.0 \mathrm{~m} / \mathrm{s}$

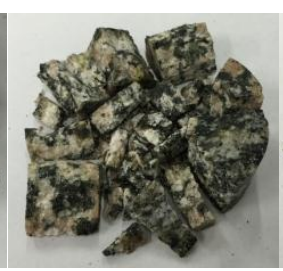

(b) $7.0 \mathrm{~m} / \mathrm{s}$

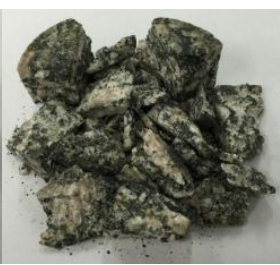

(c) $8.0 \mathrm{~m} / \mathrm{s}$

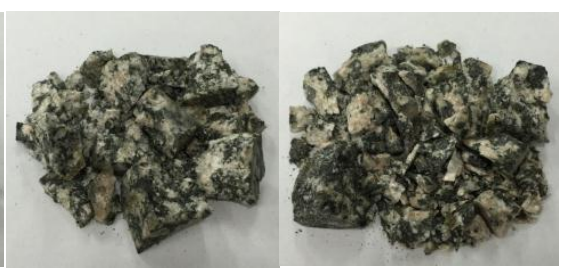

(d) $9.0 \mathrm{~m} / \mathrm{s}$ (e) $10.0 \mathrm{~m} / \mathrm{s}$

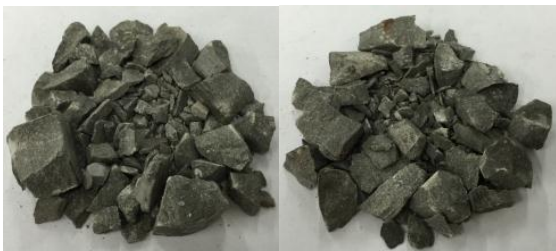

(a) $6.0 \mathrm{~m} / \mathrm{s}$

(b) $7.0 \mathrm{~m} / \mathrm{s}$

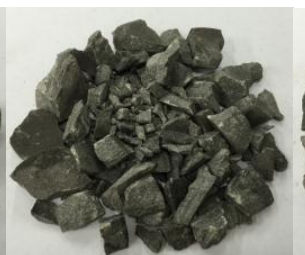

(c) $8.0 \mathrm{~m} / \mathrm{s}$

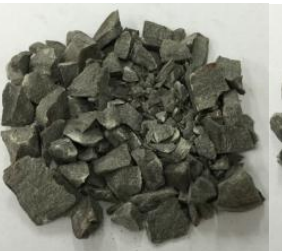

(d) $9.0 \mathrm{~m} / \mathrm{s}$

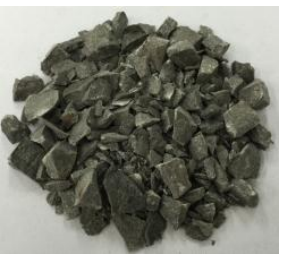

(e) $10.0 \mathrm{~m} / \mathrm{s}$

Fig. 4 Failure modes of granite and sandstone under different impact velocities

\subsection{Analysis of energy dissipation}

Based on one-dimensional stress wave theory, the stress wave energy can be indirectly calculated according to the incident, reflected and transmitted stress wave signals obtained from the SHPB test (Lundberg, 1976; Xia and Yao, 2015):

$$
\left\{\begin{array}{l}
W_{I}=\left(A_{0} C_{0} E_{0}\right) \int_{0}^{\tau} \varepsilon_{I}^{2}(t) d t \\
W_{R}=\left(A_{0} C_{0} E_{0}\right) \int_{0}^{\tau} \varepsilon_{R}^{2}(t) d t \\
W_{T}=\left(A_{0} C_{0} E_{0}\right) \int_{0}^{\tau} \varepsilon_{T}^{2}(t) d t
\end{array}\right.
$$

In Eq. (12), $W_{I}, W_{R}, W_{T}$ stand for the incident wave energy, reflection wave energy and transmission wave energy; $A_{0}, C_{0}, E_{0}$ represent the cross-sectional area, longitudinal wave velocity and elastic modulus of the bar; and $\varepsilon_{I}(t), \varepsilon_{R}(t), \varepsilon_{T}(t)$ stand for the incident, reflection and transmission strain signals, respectively.

Ignoring the energy loss between the rock specimen and bars, the mathematical expression of total absorption energy and energy consumption density of rock is as follows: 


$$
\left\{\begin{array}{l}
W_{L}=W_{I}-\left(W_{R}+W_{T}\right) \\
E_{v}=\frac{W_{L}}{V}
\end{array}\right.
$$

On the basis of the SHPB test data, the energy dissipation of rock is calculated according to Equations (12) and (13); the results are listed in Table 4.

Table 4 Calculated rock energy consumption under different impact velocities

\begin{tabular}{ccccccc}
\hline $\begin{array}{c}\text { Rock } \\
\text { sample }\end{array}$ & $\begin{array}{c}\text { Impact } \\
\text { velocity }(\mathrm{m} / \mathrm{s})\end{array}$ & $\begin{array}{c}\text { Incident } \\
\text { energy }(\mathrm{J})\end{array}$ & $\begin{array}{c}\text { Reflected } \\
\text { energy }(\mathrm{J})\end{array}$ & $\begin{array}{c}\text { Transmitted } \\
\text { energy }(\mathrm{J})\end{array}$ & $\begin{array}{c}\text { Absorbed } \\
\text { energy }(\mathrm{J})\end{array}$ & $\begin{array}{c}\text { Energy density } \\
\left(\mathrm{J} / \mathrm{cm}^{3}\right)\end{array}$ \\
\hline G-1 & 6.0 & 288.96 & 148.32 & 48.40 & 92.24 & 1.88 \\
G-2 & 7.0 & 317.59 & 162.20 & 59.72 & 95.67 & 1.95 \\
G-3 & 8.0 & 365.17 & 172.35 & 74.58 & 118.24 & 2.41 \\
G-4 & 9.0 & 415.65 & 209.96 & 68.81 & 136.88 & 2.79 \\
G-5 & 10.0 & 494.84 & 255.01 & 86.75 & 153.08 & 3.12 \\
\hline S-1 & 6.0 & 296.85 & 121.80 & 69.07 & 105.98 & 2.16 \\
S-2 & 7.0 & 311.98 & 141.85 & 58.27 & 111.86 & 2.28 \\
S-3 & 8.0 & 372.27 & 168.52 & 68.34 & 135.41 & 2.76 \\
S-4 & 9.0 & 430.91 & 179.99 & 88.03 & 162.89 & 3.32 \\
S-5 & 10.0 & 508.48 & 226.74 & 97.26 & 184.48 & 3.76 \\
\hline
\end{tabular}

As calculated from the data in Table 3 and Table 4, the relationship between energy consumption density and average size of rock fragments can be observed in Figure 5.

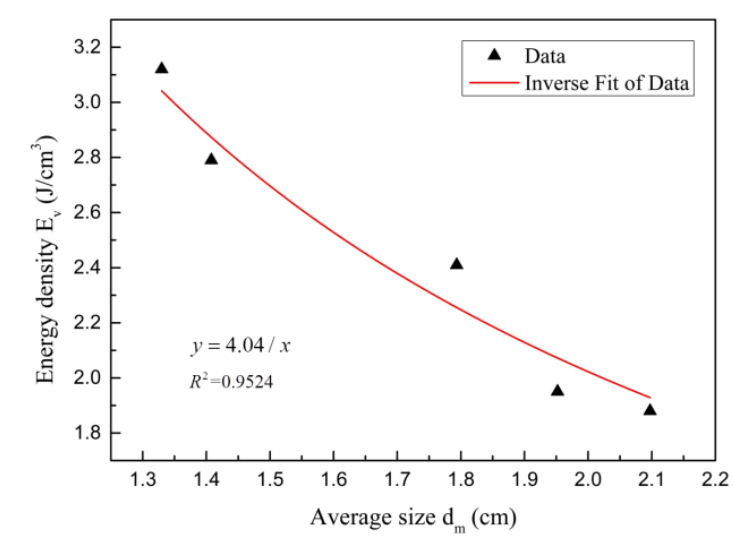

(a) Granite

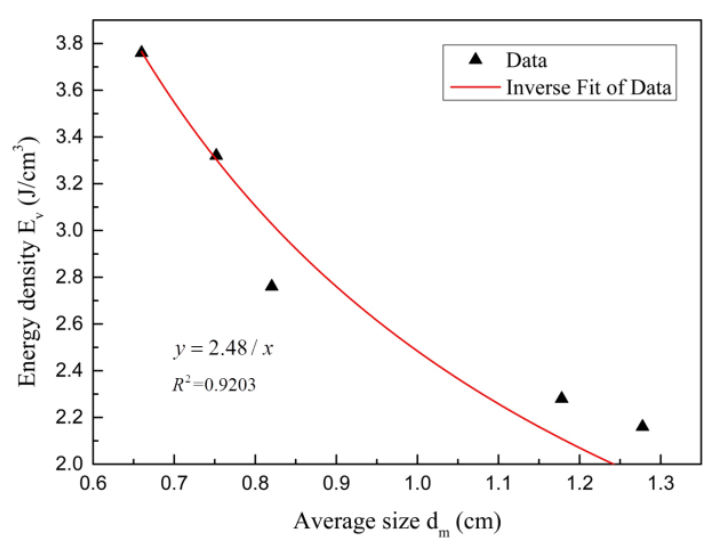

(b) Sandstone

Fig. 5 Relationship between energy density and average size

As shown in Fig. 5, the energy consumption density-average size curves of granite and sandstone are similar, and there exists a very significant inverse proportional relationship between them. With increasing energy consumption density, the average size decreases significantly, 
resulting in the fracture surface area increasing accordingly. The relationship between these two factors can be represented as:

$$
E_{v}=\frac{k}{d_{m}}
$$

where $k$ is the coefficient related to rock properties and the manner of rock breaking. For granite, $k=4.04$; for sandstone, $k=2.48$.

According to the definition, the fracture surface energy and energy consumption density can also be expressed as:

$$
\left\{\begin{array}{l}
E_{s}=\frac{W}{\Delta A} \\
E_{v}=\frac{W}{V}
\end{array}\right.
$$

where $\Delta A$ is the increment of fracture surface area. Assuming the rock with volume $V$ is converted into the corresponding cube with side length $D$, then the surface area of the rock is $A_{0}=6 D^{2}$; after fragmentation, the total number of fragments is $n=\frac{\lambda^{3} V}{d_{m}^{3}}$, and the total surface area is $\sum A=\frac{6 \lambda V}{d_{m}} ; \lambda$ is the correction factor of error caused the difference in the actual shape of the fragments and an ideal cube, $\lambda=1.3$ ( $\mathrm{Li}$ et al. 2009). Thus, a formula for the increment of fracture surface area is derived:

$$
\Delta A=\sum A-A_{0}=\frac{6 \lambda V}{d_{m}}-6 D^{2}
$$

Combining Equations (15) and (16), the relationship between energy consumption density and fracture surface energy can be calculated as

$$
\frac{E_{v}}{E_{s}}=\frac{6 \lambda}{d_{m}}-\frac{6}{D}
$$

When $D>>d_{m}$, Equation (17) can be simplified as

$$
E_{v}=\frac{6 \lambda}{d_{m}} E_{s}
$$


Introducing (14) into (18) and performing the appropriate transformation, the calculated formula of fracture surface energy is as follows:

$$
E_{s}=\frac{k}{6 \lambda}
$$

Therefore, the fracture surface energy of granite and sandstone, respectively, are $0.518 \mathrm{~J} / \mathrm{cm}^{2}$ and $0.318 \mathrm{~J} / \mathrm{cm}^{2}$. According to the size distribution of rock fragments and calculated values of surface energy, the energy consumption density of two types of rock under different impact velocities can be determined using the theoretical model (7) and is shown in Table 5 .

Table 5 Calculated rock crushing energy density

\begin{tabular}{ccccc}
\hline $\begin{array}{c}\text { Rock } \\
\text { sample }\end{array}$ & $\begin{array}{c}\text { Impact } \\
\text { velocity }(\mathrm{m} / \mathrm{s})\end{array}$ & $\begin{array}{c}\text { Test value of energy } \\
\text { density }\left(\mathrm{J} / \mathrm{cm}^{3}\right)\end{array}$ & $\begin{array}{c}\text { Theoretical value of } \\
\text { energy density }\left(\mathrm{J} / \mathrm{cm}^{3}\right)\end{array}$ & $\begin{array}{c}\text { Relative } \\
\text { error }(\%)\end{array}$ \\
\hline G-1 & 6.0 & 1.88 & 2.16 & 14.93 \\
G-2 & 7.0 & 1.95 & 2.23 & 14.13 \\
G-3 & 8.0 & 2.41 & 2.72 & 12.70 \\
G-4 & 9.0 & 2.79 & 3.10 & 11.16 \\
G-5 & 10.0 & 3.12 & 3.45 & 10.49 \\
\hline S-1 & 6.0 & 2.16 & 2.44 & 13.09 \\
S-2 & 7.0 & 2.28 & 2.57 & 12.72 \\
S-3 & 8.0 & 2.76 & 3.03 & 9.60 \\
S-4 & 9.0 & 3.32 & 3.59 & 8.08 \\
S-5 & 10.0 & 3.76 & 4.04 & 7.39 \\
\hline
\end{tabular}

As can be observed from Table 5, the theoretical values of energy consumption density are basically consistent with experimental results, and the relative error is controlled within $15 \%$, which demonstrates that the model (7) is valid and can be used to predict the energy required for rock crushing under impact loading with reasonable accuracy.

\section{Conclusions}

The essence of rock fragmentation is the process of energy dissipation. In this paper, the fractal energy consumption model is established based on fractal rock mechanics and fracture mechanics theory. Furthermore, dynamic uniaxial compressive tests on two types of rock under five different impact velocities are conducted using the SHPB device, and the characteristics of the rock fragment distribution and energy dissipation of rock dynamic breaking are analyzed. The main conclusions are as follows: 
(1) The rock fragments obtained from SHPB dynamic tests exhibit a prominent fractal character, with the fractal dimension values varying between 1.7 and 2.6; the larger the fractal dimension, the higher the degree of rock fragmentation.

(2) There exists a very significant inverse relationship between the energy consumption density and average size of rock fragments: the average size decreases with the increasing energy consumption density. The energy absorption of rock during the fragmentation process is essentially consumed by forming new fracture surfaces; along with the increase of absorbed energy, the amount of fragments and new fracture surfaces increases.

(3) The fracture surface energy of granite and sandstone is determined from SHPB tests to be $0.518 \mathrm{~J} / \mathrm{cm}^{2}$ and $0.318 \mathrm{~J} / \mathrm{cm}^{2}$, respectively. The theoretical values of the energy consumption density are in good agreement with the experimental results, with a relative error below $15 \%$.

(4) The fractal energy consumption model proposed in this paper can be used to evaluate the resistance of rock crushing under impact loading and to predict energy consumption based on the distribution of rock fragments conveniently and easily and is expected to provide useful guidance for improving the efficiency of rock dynamic breaking.

\section{Acknowledgements}

The authors are grateful for the Project Supported by National Science Foundation of China for Distinguished Young Scholars (No. 51325402) and National Science Foundation of China (No. 51234006).

\section{References}

[1] Xu, X.H., Yu, J., 1984. Rock fragmentation. Beijing: China Coal Industry Press.

[2] Wang, K.X., 1999. Research and application of percussion rotary drilling technology in petroleum drilling. Oil Drilling \& Production Technology 21(5): 5-9 in Chinese.

[3] Wiercigroch, M., Wojewoda, J., Krivtsov, A.M., 2005. Dynamics of ultrasonic percussive drilling of hard rocks. Journal of Sound and Vibration 280: 739-757.

[4] Li, H., Butt, S., Munaswamy, K. et al., 2010. Experimental investigation of bit vibration on rotary drilling penetration rate. Proceedings of the $44^{\text {th }}$ US Rock Mechanics Symposium and $5^{\text {th }}$ U.S.-Canada Rock Mechanics Symposium.

[5] Akbari, B., Butt, S.D., Munaswamy, K., Arvani, F., 2011. Dynamic single PDC cutter rock drilling modeling and simulations focusing on rate of penetration using distinct element method. Proceedings of the $45^{\text {th }}$ US Rock Mechanics/Geomechanics Symposium.

[6] Franca, L.F.P., 2011. A bit-rock interaction model for rotary-percussive drilling. International 
Journal of Rock Mechanics and Mining Sciences 48 (5): 827-835.

[7] Li, S.Q., Yan, T., Li, W. et al., 2015. Modeling of vibration response of rock by harmonic impact. Journal of Natural Gas Science and Engineering 23: 90-96.

[8] Hustrulid, W.A., Fairhurst, C., 1971. A theoretical and experimental study of the percussive drilling of rock part I -theory of percussive drilling. International Journal of Rock Mechanics and Mining Science 8: 311-333.

[9] Hustrulid, W.A., Fairhurst, C., 1971. A theoretical and experimental study of the percussive drilling of rock part II -force-penetration and specific energy determinations. International Journal of Rock Mechanics and Mining Science \& Geomechanics Abstracts 8: 335-340.

[10] Hustrulid, W.A., Fairhurst, C., 1972. A theoretical and experimental study of the percussive drilling of rock partIII-experimental verification of the mathematical theory. International Journal of Rock Mechanics and Mining Science 9: 417-429.

[11] Hustrulid, W.A., Fairhurst, C., 1972. A theoretical and experimental study of the percussive drilling of rock partIV-application of the model to actual percussion drilling. International Journal of Rock Mechanics and Mining Science 9: 431-449.

[12] Carpinteri, A., Lacidogna, G., Pugno, N., 2004. Scaling of energy dissipation in crushing and fragmentation: a fractal and statistical analysis based on particle size distribution. International Journal of Fracture 129: 131-139.

[13] Lundberg, B., Okrouhlik, M., 2006. Efficiency of a percussive rock drilling process with consideration of wave energy radiation into the rock. International Journal of Impact Engineering 32: 1573-1583.

[14] Lundberg, B., Collet, P., 2010. Optimal wave with respect to efficiency in percussive drilling with integral drill steel. International Journal of Impact Engineering 37: 901-906.

[15] Marian, W., Anton, M.K., Jerzy, W., 2008. Vibrational energy transfer via modulated impacts for percussive drilling. Journal of Theoretical \& Applied Mechanics 46(3): 715-726.

[16] Sadrai, S., Meech, J.A., Tromans, D. et al., 2011. Energy efficient comminution under high velocity impact fragmentation. Minerals Engineering 24: 1053-1061.

[17] Li, X.B., Lai, H.H., Zhu, C.Z., 1988. A study of the dynamic properties and energy absorption of rocks. Mining and Metallurgical Engineering 8 (1): 15-19 in Chinese.

[18] Xu, J.Y., Lu, X.C., Zhang, J. et al., 2010. Research on energy properties of rock cyclical impact damage under confining pressure. Chinese Journal of Rock Mechanics and Engineering 29 (2): 4159-4165 in Chinese.

[19] Li, Q.Y., Gu, C.H., Li, X.B. et al., 2009. Experimental research on relationship between energy consumption and fragmentation size of skarm subjected to impact loading. Mining and Metallurgical Engineering 29 (4): 18-21 in Chinese.

[20] Mandelbrot, B.B., 1982. The fractal geometry of nature. San Francisco: Freeman and Company.

[21] Perfect, E., 1997. Fractal models for the fragmentation of rocks and soils: a review. Engineering Geology 48: 185-198.

[22] Lai, J., Wang, G., 2015. Fractal analysis of tight gas sandstones using high-pressure mercury intrusion techniques. Journal of Natural Gas Science and Engineering 24: 185-196.

[23] Hu, J., Tang, S., Zhang, S., 2016. Investigation of pore structure and fractal characteristics of the Lower Silurian Longmaxi shales in western Hunan and Hubei Provinces in China. Journal of Natural Gas Science and Engineering. doi: 10.1016/j.jngse.2015.12.024. 
[24] Nagahama, H., 1993. Fractal fragment size distribution for brittle rocks. International Journal of Rock Mechanics and Mining Sciences \& Geomechanics Abstracts 30(4): 469-471.

[25] Xie, H.P., 1996. Fractal rock mechanics. Beijing: Science Press.

[26] Turcotte, D.L., 1986. Fractals and fragmentation. Journal of Geophysical Research 91 (B2): 1921-1926.

[27] Griffith A A 1921. The phenomenon of rupture and flow in solids. Philosophical Transactions of the Royal Society of London Series A 221: 163-198.

[28] Li, S.Y., He, T.M., Yin, X.C., 2010. Introduction of rock fracture mechanics. Hefei: China University of Science and Technology Press.

[29] Standard ASTM, 2002. D2938-95 Standard test method for unconfined compressive strength of intact rock core specimens. In American Society for Testing and Materials.

[30] Lundberg, B., 1976. A split Hopkinson bar study of energy absorption in dynamic rock fragmentation. International Journal of Rock Mechanics and Mining Science \& Geomechanics Abstracts 13: 187-197.

[31] Xia, K.W., Yao, W., 2015. Dynamic rock tests using split Hopkinson (Kolsky) bar system-a review. Journal of Rock Mechanics and Geotechnical Engineering 7: 27-59. 